\title{
International and indigenous diagnoses of mental disorder among Vietnamese living in Vietnam and Australia
}

Zachary Steel, Derrick Silove, Nguyen Mong Giao, Thuy Thi Bich Phan, Tien Chey, Anna Whelan, Adrian Bauman and Richard A. Bryant

\section{Background}

Whether the prevalence rates of common mental disorders can be compared across countries depends on the cultural validity of the diagnostic measures used.

\section{Aims}

To investigate the prevalence of Western and indigenously defined mental disorders among Vietnamese living in Vietnam and in Australia, comparing the data with an Australian-born sample.

\section{Method}

Comparative analysis of three multistage population surveys, including samples drawn from a community living in the Mekong Delta region of Vietnam $(n=3039)$, Vietnamese immigrants residing in New South Wales, Australia $(n=1161)$, and an Australian-born population $(n=7961)$. Western-defined mental disorders were assessed by the composite International Diagnostic Interview (CIDI) 2.0 and included DSM-IV anxiety, mood and substance use disorders as well as the ICD-10 category of neurasthenia. The Vietnamese surveys also applied the indigenously based Phan Vietnamese Psychiatric Scale (PVPS). Functional impairment and service use were assessed.

\section{Results}

The prevalence of CIDI mental disorders for Mekong Delta Vietnamese was 1.8\% compared with 6.1\% for Australian Vietnamese and $16.7 \%$ for Australians. Inclusion of PVPS mental disorders increased the prevalence rates to $8.8 \%$ for Mekong Delta Vietnamese and $11.7 \%$ for Australian Vietnamese. Concordance was moderate to good between the CIDI and the PVPS for Australian Vietnamese (area under the curve (AUC)=0.77) but low for Mekong Vietnamese (AUC=0.59). PVPS- and CIDI-defined mental disorders were associated with similar levels of functional impairment.

\section{Conclusions}

Cultural factors in the expression of mental distress may influence the prevalence rates of mental disorders reported across countries. The findings have implications for assessing mental health needs at an international level.

\section{Declaration of interest}

None.

of Ho Chi Minh City on the banks of the Hậu Giang river, is the fifth largest city in Vietnam and the main urban centre of the Mekong Delta region (population of 1121 141). The province of Hậu Giang lies adjacent to Cần Thơ City and covers a rural population of 772239 .

The survey applied a multistage probabilistic cluster sampling frame with the commune or hamlet (the smallest geographic area for which census information is available) specified as the primary sampling unit. The first stage applied probability proportional to size sampling to identify 15 of a pool of 478 hamlets in Hậu Giang province and 16 from a pool of 503 hamlets in Cần Thơ City. In each hamlet, 100 consecutive households were selected using a random commencement point. Within each household, a single respondent aged 18 years or older was selected using a Kish grid without replacement for non-response. Overall, 3039 people living in 3100 households agreed to participate, forming the Mekong Delta Vietnamese sample (response rate 98\%).

Twenty-five local personnel ( 5 mental health physicians, 16 mental health nurses and 4 general staff) conducted the interviews. All interviewers received $40 \mathrm{~h}$ of initial training in the administration of the research instruments, as well as ongoing supervision.

\section{Australian Vietnamese survey}

The Australian Vietnamese survey was conducted between June 1999 and May 2000. A full description of survey methods has been 
provided elsewhere. ${ }^{6}$ Sampling of private dwellings was carried out across five local government areas in New South Wales, Australia, housing 41487 people or $75 \%$ of the total adult Vietnamese population resident in that state. A probability proportional to size cluster-sampling method was applied to select 44 census collection districts in which all identified households were approached. The occupants were contacted by an introductory letter and this was followed by a face-to-face visit. A Vietnamese-speaking bilingual interviewer then ascertained whether the household was occupied by persons of Vietnamese origin. Of the 6224 private dwellings approached, 1413 housed at least one Vietnamese person. A single respondent aged 18 years or older was randomly selected for interview. Interviews were conducted by trained bilingual Vietnamese-speaking lay workers. The sample included 1161 individuals, a response rate of $82 \%$. Participants completed the interviews in Vietnamese $(98.6 \%)$ or English (1.4\%).

\section{Australian Bureau of Statistics survey}

The Australian Bureau of Statistics survey, described elsewhere, ${ }^{7}$ was conducted between May 1997 and August 1997, consisting of a nationwide stratified multistage probability sample of 13624 private dwellings. Interviews were conducted with 10641 individuals randomly selected from each household (response rate of $78 \%$ ). Responses of the 7961 participants born in Australia (Australians) were extracted for analysis.

\section{Survey instruments}

\section{Diagnostic assessment}

All three surveys applied the Composite International Diagnostic Interview (CIDI) 2.0, a lay administered instrument yielding DSM-IV diagnoses. ${ }^{8}$ The measure has been widely employed in international psychiatric epidemiological studies. The CIDI identified the 12-month prevalence of DSM-IV anxiety disorders (panic disorder, agoraphobia, social phobia, generalised anxiety disorder, obsessive-compulsive disorder and post-traumatic stress disorder), mood disorders (depression, dysthymia, mania, hypomania and bipolar disorder) and substance use disorders (alcohol and substance harmful use/misuse and dependence). The ICD $-10^{9}$ diagnosis of neurasthenia was included since there is no equivalent category in DSM-IV.

The two Vietnamese studies also included the Phan Vietnamese Psychiatric Scale (PVPS), a questionnaire designed to identify culturally relevant idioms and expressions of psychological distress in that ethnic group. ${ }^{10}$ A full description of the development of the measure has been published previously ${ }^{10}$ and only a summary of the procedure will be provided herein. The measure was developed in sequential stages. First, items describing a wide range of emotional states were derived from a comprehensive review of both the medical and general Vietnamese-language literature. Next, a series of ethnographic studies involving members of the Vietnamese community yielded further items for inclusion in the pool. Items were then subjected to psychometric testing based on responses of Vietnamese samples attending psychiatric and general health clinics. From these analyses, three broad symptom constellations emerged, broadly recognisable as the domains of anxiety, depression and somatisation. The final measure included a 26-item depression scale, a 13 -item anxiety scale and a 14 -item somatisation scale. Psychometric tests revealed sound internal consistency $(r=0.87-0.95)$ and test-retest reliability $(r=0.81-0.89)$ for the scales. Criterion validity was assessed by comparing the anxiety, depression and somatisation sub-scales with diagnoses made by naturalist healers
( $\kappa=0.45-0.71)$, psychiatrists $(\kappa=0.49-0.62)$ and by structured diagnostic instruments $(\kappa=0.61-0.69)$ demonstrating satisfactory diagnostic agreement. To maintain the cultural foundations of the measure, threshold scores were adopted from diagnoses made by naturalist healers. ${ }^{10}$ In the present study, PVPS symptoms were recorded for the preceding 12 months to ensure consistency with the CIDI.

\section{Disability}

All surveys included two measures of disability: the Medical Outcomes Study Short Form-12 (MOS-SF-12) generates a physical (PCS) and a mental (MCS) health component functioning score, with lower scores indicating higher levels of disability. ${ }^{6}$ The PCS includes items assessing physical functioning, including difficulties in role performance attributed to physical symptoms, bodily pain and general health. The MCS includes items assessing vitality, social functioning, role performance difficulties attributed to emotional problems and mental health. The PCS and MCS were categorised according to two levels of disability: none or mild (40 or above) and moderate to severe (below 40). ${ }^{6}$

The number of disability days was based on two questions ${ }^{7}$ assessing the number of days respondents were unable to work or to carry out normal activities, and the number of days respondents had to significantly reduce their activity because of ill health. The combined index was stratified according to three levels: no days of disability; $1-5$ days of disability; and 5+ days of disability. ${ }^{6}$

\section{Service utilisation}

Contact with service providers for all health and mental health problems in the previous 12 months was recorded. ${ }^{7}$ Service providers included primary care physicians; a mental health practitioner; and, in the Vietnamese samples, a traditional healer (Chinese doctor, acupuncturist, herbalist, folk healer/witchcraft practitioner and fortune teller/cosmologist). ${ }^{6}$

\section{Translation-back-translation}

The CIDI and MOS-SF-12 were translated in Australia using established methods ${ }^{6,11}$ with minor discrepancies being reconciled by a Vietnamese mental health professional and a panel of seven bilingual healthcare interpreters. Minor modifications relevant to local language usage were made for the Mekong Delta survey by five senior mental health staff from Cần Tho health service.

Across all sites, interviewers administered the CIDI and other measures using prompt cards and a computerised data-entry system.

\section{Statistical analysis}

All three samples were stratified according to the age and gender distribution of the target population. For the Mekong Delta Vietnamese, the age and gender distribution of the general population was derived from the 1999 Vietnam census of housing and population. For Australian Vietnamese, weighting was based on the New South Wales Vietnamese population derived from the 2001 Australian census. The Australian sample was weighted according to the age and gender distribution of the 1996 Australian population. For the two Vietnamese samples, standard errors for prevalence estimates were calculated using the SAS software package 9.1.3 for Windows, adjusting for clustering effects. For Australians, a jackknife method using 30 replicate weights was applied to calculate the standard errors of the 
prevalence estimates in accordance with the guidelines provided by the Australian Bureau of Statistics. ${ }^{7}$

Demographic characteristics of the three populations surveyed are presented as weighted counts and prevalence estimates (\%). Chi-squared tests were used to compare categorical variables. Cohen's kappa $(\kappa)$ and the area under the receiver operating characteristic curve (AUC) were used to assess the level of diagnostic agreement between the CIDI and PVPS. The $\kappa$-statistic ranges from 0.0 to 1.0 , providing a measure of agreement corrected for chance. It is sensitive to population prevalence rates, however, even when sensitivity and specificity estimates remain constant across samples. In effect, this means that the $\kappa$ is likely to be higher in clinic samples than in population-based studies. ${ }^{12}$ The AUC addresses this limitation because it is not sensitive to prevalence rates. ${ }^{12,13}$ Estimates for AUC range from 0.5 to 1.0. A score of 0.9 or greater indicates near perfect agreement; $0.8-0.9$, substantial agreement; $0.7-0.8$, moderate agreement; 0.6-0.7 fair agreement; and less than 0.6 , slight agreement. ${ }^{13,14}$

\section{Results}

The average period of residency for Australian Vietnamese in Australia was 11.3 years (s.d.=5.9). Table 1 presents weighted age and gender characteristics for the three samples. There were no gender differences $\left(\chi_{(2)}^{2}=1.90, P>0.05\right)$ but the Vietnamese samples were younger than Australians $\left(\chi_{(10)}^{2}=405, P<0.0001\right)$. More Mekong Delta Vietnamese were married and fewer were divorced $\left(\chi_{(6)}^{2}=327.3, P<0.0001\right)$. Australian Vietnamese had higher levels of education compared with Mekong Delta Vietnamese $\left(\chi_{(4)}^{2}=825, P<0.0001\right)$. Australians had higher levels of tertiary education than either of the Vietnamese groups.
Workforce participation was lower among Mekong Delta Vietnamese $\left(49.9 ; \chi_{(4)}^{2}=687, P<0.0001\right)$.

\section{Prevalence of CIDI mental disorders}

Table 2 presents the weighted prevalence estimates with design corrected standard errors for CIDI mood, anxiety and substance use disorders as well as ICD-10 neurasthenia. The prevalence of all CIDI disorders for the Mekong Delta Vietnamese was 1.9\% compared with $6.7 \%$ for Australian Vietnamese and $17.1 \%$ for Australians.

The pattern was consistent when anxiety and depressive disorders were examined separately. The rates of substance use disorders were similarly low for the two Vietnamese samples (1.1\% for Mekong Delta Vietnamese and 1.6\% for Australian Vietnamese), about a fifth of the prevalence for Australians $(8.8 \%)$. Both Vietnamese samples had low rates of neurasthenia compared with Australians.

\section{Prevalence of PVPS mental disorders}

Table 2 presents prevalence rates yielded by the PVPS. Mekong Delta Vietnamese (7.4\%) and Australian Vietnamese (8.4\%) had similar overall prevalence rates, with the same pattern emerging for the individual domains of anxiety, depression and somatisation. Somatisation was the most commonly assigned diagnosis in both samples, followed by anxiety and then depression.

\section{Comparing CIDI and PVPS cases}

Table 3 compares data from the CIDI and the PVPS for the Vietnamese groups. The aggregated prevalence of CIDI and PVPS disorders was $8.8 \%$ for the Mekong Delta Vietnamese, with the PVPS identifying $84.1 \%$ and the CIDI $21.9 \%$ of all participants

\begin{tabular}{|c|c|c|c|c|c|c|}
\hline & \multicolumn{2}{|c|}{ Mekong Delta Vietnamese } & \multicolumn{2}{|c|}{ Australian Vietnamese } & \multicolumn{2}{|r|}{ Australian } \\
\hline & $n$ & $\begin{array}{c}\text { Estimated prevalence, } \\
\% \text { (s.e.) }\end{array}$ & $n$ & $\begin{array}{c}\text { Estimated prevalence, } \\
\% \text { (s.e.) }\end{array}$ & $n$ & $\begin{array}{c}\text { Estimated prevalence, } \\
\% \text { (s.e.) }\end{array}$ \\
\hline \multicolumn{7}{|l|}{ Gender } \\
\hline Male & 1431 & $47.1(1.2)$ & 572 & $49.3(2.0)$ & 3839 & $48.2(0.6)$ \\
\hline Female & 1608 & $52.9(1.2)$ & 589 & $50.7(2.0)$ & 4122 & $51.8(0.6)$ \\
\hline \multicolumn{7}{|l|}{ Age, years } \\
\hline $18-24$ & 757 & $24.9(1.1)$ & 192 & $16.5(2.3)$ & 1193 & $15.0(0.7)$ \\
\hline $25-34$ & 849 & $27.9(1.3)$ & 326 & $28.1(2.1)$ & 1775 & $22.3(0.8)$ \\
\hline $35-44$ & 616 & $20.3(0.6)$ & 346 & $29.8(1.8)$ & 1654 & $20.8(0.8)$ \\
\hline $45-54$ & 355 & $11.7(0.7)$ & 157 & $13.5(1.2)$ & 1268 & $15.9(0.7)$ \\
\hline $55-64$ & 187 & $6.2(0.6)$ & 52 & $4.5(0.6)$ & 857 & $10.8(0.6)$ \\
\hline $65+$ & 274 & $9.0(0.7)$ & 88 & $7.6(1.0)$ & 1215 & $15.3(0.7)$ \\
\hline \multicolumn{7}{|l|}{ Marital status } \\
\hline Never married & 818 & $26.9(1.1)$ & 313 & $26.9(2.5)$ & 1834 & $23.0(0.9)$ \\
\hline Married & 2153 & $70.8(1.1)$ & 739 & $63.7(2.4)$ & 5038 & $63.3(1.0)$ \\
\hline Separated/divorced & 19 & $0.6(0.1)$ & 74 & $6.4(0.8)$ & 619 & $7.8(0.6)$ \\
\hline Widowed & 49 & $1.6(0.3)$ & 33 & $2.9(0.6)$ & 471 & $5.9(0.5)$ \\
\hline \multicolumn{7}{|l|}{ Highest qualification/trade } \\
\hline None/at school/ $<12$ years & 1900 & $61.5(2.8)$ & 689 & $59.4(2.0)$ & 2842 & $35.7(0.5)$ \\
\hline Secondary or vocational training & 739 & $23.9(1.5)$ & 358 & $30.8(2.2)$ & 4008 & $50.3(0.6)$ \\
\hline Tertiary & 380 & $12.3(2.2)$ & 114 & $9.8(1.5)$ & 1111 & $14.0(0.4)$ \\
\hline \multicolumn{7}{|l|}{ Employment status } \\
\hline Employed & 1201 & $39.5(1.7)$ & 495 & $42.7(2.0)$ & 5135 & $64.5(0.6)$ \\
\hline Unpaid labour & 1522 & $50.1(1.9)$ & 574 & $49.5(1.9)$ & 2503 & $31.4(0.6)$ \\
\hline Unemployed/not in workforce & 315 & $10.4(1.0)$ & 91 & $7.9(1.0)$ & 323 & $4.1(0.3)$ \\
\hline \multicolumn{7}{|l|}{ Housing } \\
\hline Owner & 3001 & $98.8(0.3)$ & 375 & $32.3(2.6)$ & 5037 & $63.3(0.6)$ \\
\hline Renting privately/from government & 21 & $0.7(0.2)$ & 644 & $55.5(3.1)$ & 1968 & $24.7(0.6)$ \\
\hline Other & 16 & $0.5(0.2)$ & 141 & $12.2(1.7)$ & 956 & $12.0(0.4)$ \\
\hline
\end{tabular}




\begin{tabular}{|c|c|c|c|c|c|c|}
\hline & \multicolumn{2}{|c|}{ Mekong Delta Vietnamese } & \multicolumn{2}{|c|}{ Australian Vietnamese } & \multicolumn{2}{|r|}{ Australian } \\
\hline & $n$ & $\begin{array}{c}\text { Estimated prevalence, } \\
\% \text { (s.e.) }\end{array}$ & $n$ & $\begin{array}{c}\text { Estimated prevalence, } \\
\text { \% (s.e.) }\end{array}$ & $n$ & $\begin{array}{c}\text { Estimated prevalence, } \\
\% \text { (s.e.) }\end{array}$ \\
\hline \multicolumn{7}{|l|}{ DSM-IV disorders } \\
\hline Total DSM-IV disorders & 58 & $1.9(0.3)$ & 77 & $6.7(1.0)$ & 1365 & $17.1(0.4)$ \\
\hline DSM-IV anxiety disorders & 12 & $0.4(0.1)$ & 35 & $3.1(0.8)$ & 467 & $5.9(0.3)$ \\
\hline Panic/agoraphobia & 5 & $0.1(0.1)$ & 6 & $0.6(0.4)$ & 129 & $1.6(0.1)$ \\
\hline Social phobia & 1 & $0.0(0.0)$ & 4 & $0.3(0.3)$ & 123 & $1.5(0.1)$ \\
\hline Generalised anxiety disorder & 3 & $0.1(0.1)$ & 8 & $0.7(0.2)$ & 217 & $2.7(0.2)$ \\
\hline Obsessive-compulsive disorder & 3 & $0.1(0.1)$ & 6 & $0.5(0.2)$ & 56 & $0.7(0.1)$ \\
\hline Post-traumatic stress disorder & 2 & $0.1(0.0)$ & 17 & $1.5(0.4)$ & 114 & $1.4(0.1)$ \\
\hline DSM-IV mood disorders & 14 & $0.4(0.2)$ & 30 & $2.6(0.5)$ & 563 & $7.1(0.3)$ \\
\hline Major depression & 9 & $0.3(0.2)$ & 21 & $1.8(0.4)$ & 533 & $6.7(0.3)$ \\
\hline Dysthymia & 3 & $0.1(0.1)$ & 11 & $1.0(0.3)$ & 38 & $0.5(0.1)$ \\
\hline DSM-IV substance disorders & 34 & $1.1(0.3)$ & 19 & $1.6(0.6)$ & 699 & $8.8(0.3)$ \\
\hline Alcohol use disorders & 33 & $1.1(0.3)$ & 13 & $1.1(0.5)$ & 533 & $6.7(0.3)$ \\
\hline Drug use disorders & 1 & $0.0(0.0)$ & 6 & $0.5(0.3)$ & 258 & $3.2(0.2)$ \\
\hline ICD-10 neurasthenia & 3 & $0.1(0.1)$ & 12 & $1.0(0.3)$ & 134 & $1.7(0.1)$ \\
\hline \multicolumn{7}{|l|}{ PVPS disorders } \\
\hline Total PVPS disorders & 224 & $7.4(0.8)$ & 98 & $8.4(0.7)$ & & \\
\hline Depression & 37 & $1.2(0.7)$ & 27 & $2.4(0.5)$ & & \\
\hline Anxiety & 122 & $4.0(0.2)$ & 42 & $3.6(0.5)$ & & \\
\hline Somatisation & 162 & $5.3(0.6)$ & 82 & $7.1(0.6)$ & & \\
\hline
\end{tabular}

identified by both systems. The PVPS identified 208 unique cases, the CIDI 42 unique cases and both systems 16 cases, indicating minimum diagnostic overlap $(\mathrm{AUC}=0.59)$. For Australian Vietnamese, the two measures yielded a combined prevalence of $11.7 \%$. The PVPS identified $72.2 \%$ of all cases and the CIDI 57\%. The PVPS identified 58 unique cases, the CIDI 38 cases, and both systems 40 cases, representing a moderate degree of diagnostic agreement (AUC=0.77).

Table 3 indicates that in both Vietnamese populations, depression was the domain with the greatest level of concordance across the diagnostic systems (Mekong Delta Vietnamese, 64.8\%, Australian Vietnamese, 92\%) followed by PVPS anxiety (Mekong Delta Vietnamese, 34.7\%; Australian Vietnamese, 80.7\%). The PVPS somatisation scale showed a low level of overlap with CIDI neurasthenia (Mekong Delta Vietnamese, 28.5\%; Australian Vietnamese, 61.9\%). Virtually all those with neurasthenia also had PVPS somatisation, but a larger number of Vietnamese fell into the latter category alone.

\section{Functional impairment}

In the first set of analyses, individuals identified by either diagnostic measure were examined. In all three samples, being assigned a mental disorder was associated with substantial functional impairment (Table 4). A greater percentage of participants from the Mekong Delta Vietnamese (48.3\%) and Australian Vietnamese $(48.3 \%)$ groups reported five or more disability days compared with the Australian group (28.1\%) $\left(\chi_{(2)}^{2}=23.00, P \leqslant 0.0001\right)$. Findings from the MOS-SF-12 PCS scale indicated that Australian Vietnamese $(52.2 \%)$ with a mental disorder reported the greatest level of impairment in physical functioning, followed by Mekong Delta Vietnamese (34.2\%) and Australians $\quad(22.6 \%) \quad\left(\chi_{(2)}^{2}=64.95, \quad P \leqslant 0.001\right)$. Australian Vietnamese $(37.9 \%)$ with a CIDI or PVPS disorder and Australians $(35.2 \%)$ with a CIDI disorder reported similar levels of impairment in mental health functioning, whereas Mekong Delta Vietnamese reported lower levels of dysfunction on that index $(20.8 \%)\left(\chi_{(2)}^{2}=22.52, P \leqslant 0.001\right)$.
Levels of functional impairment were then compared across the two diagnostic systems. For the Australian Vietnamese, those identified by the CIDI and PVPS did not differ across any of the three indices of functional impairment (MOS-SF-12 MCS: $\chi_{(1)}^{2}=0.059, P=0.808 ;$ MOS-SF-12 PCS: $\chi_{(1)}^{2}=1.552, P=0.213$; disability days: $\left.\chi_{(2)}^{2}=5.02, P=0.081\right)$. For the Mekong Delta Vietnamese, the overall level of disability associated with the two diagnostic systems was similar (five or more disability days: CIDI $36.4 \% \quad v$. PVPS $51.1 \%, \chi_{(1)}^{2}=6.25, P=0.45$; MOS-SF-12 MCS: CIDI $18 \% v$. PVPS $\left.22.2 \%, \chi_{(1)}^{2}=6.25, P=0.45\right)$. Nevertheless, for the MOS-SF-12, people identified by the PVPS reported greater impairment in physical functioning compared with the CIDI (MOS-SF-12 PCS: CIDI $20.3 \%$ v. PVPS $38 \%, \chi_{(1)}^{2}=6.25$, $P=0.012$ ).

\section{Health service utilisation}

Table 5 shows that $21.5 \%$ of Mekong Delta Vietnamese with a mental disorder had a consultation with a primary care physician in the previous 12 months compared with over $83.5 \%$ of Australian Vietnamese and Australians. Primary care consultations specific to a mental health problem were low (1.9\%) for Mekong Delta Vietnamese compared with Australian Vietnamese (24.4\%) and Australians (30.9\%). Australians with a disorder were more likely to consult a mental health specialist than affected Australian Vietnamese $(24 \%$ v. $10.2 \%)$. Vietnamese with mental disorders rarely consulted traditional healers, with Mekong Delta Vietnamese having notably low rates.

\section{Discussion}

Our study revealed a low prevalence of common CIDI-defined mental disorders for Vietnamese living in Australia and in Vietnam compared with an Australian-born sample and, more generally, with other studies undertaken in high-income countries of the West. ${ }^{1,2}$ The findings, therefore, add to the already substantial evidence indicating low rates of DSM-derived 

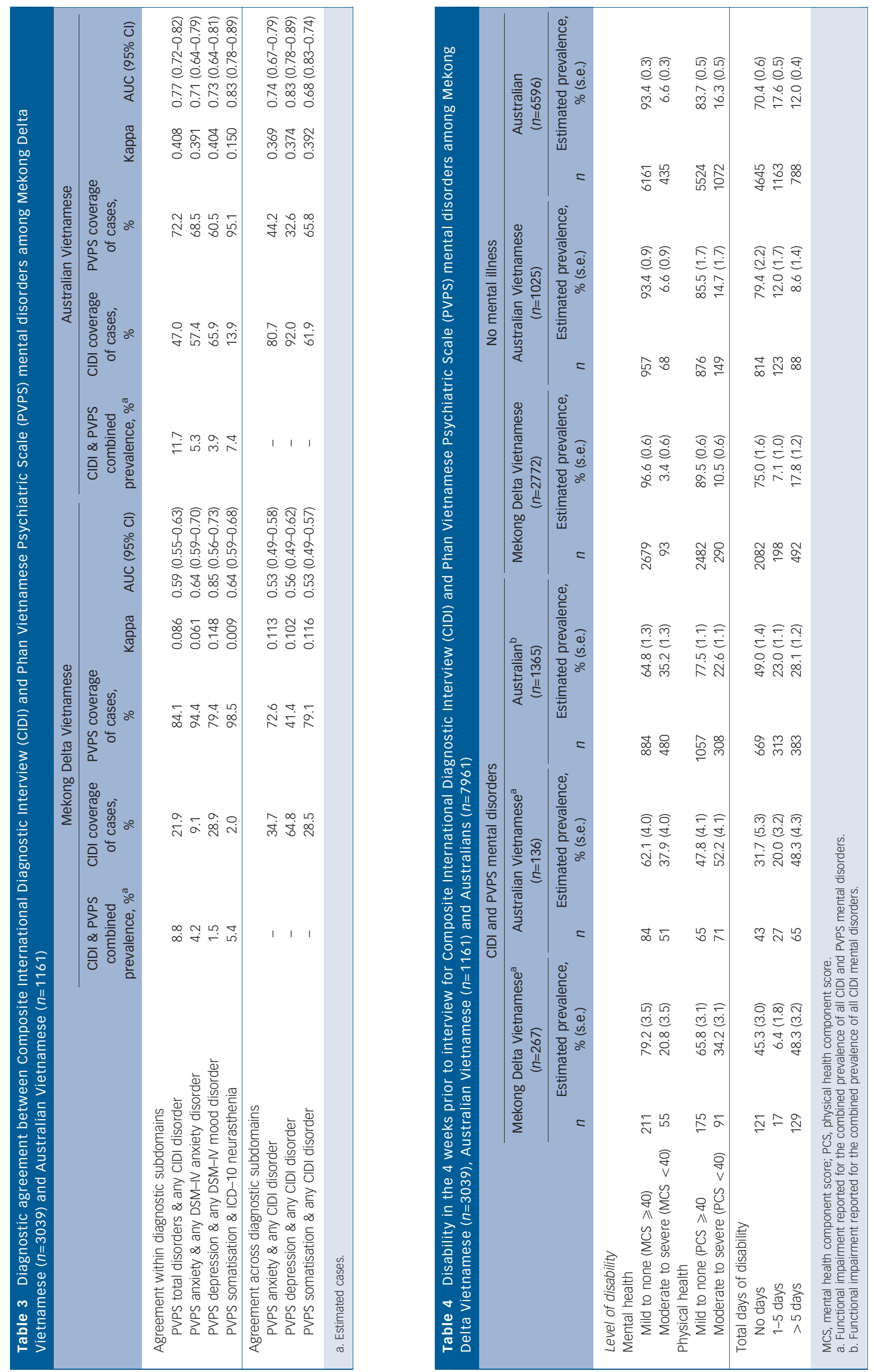


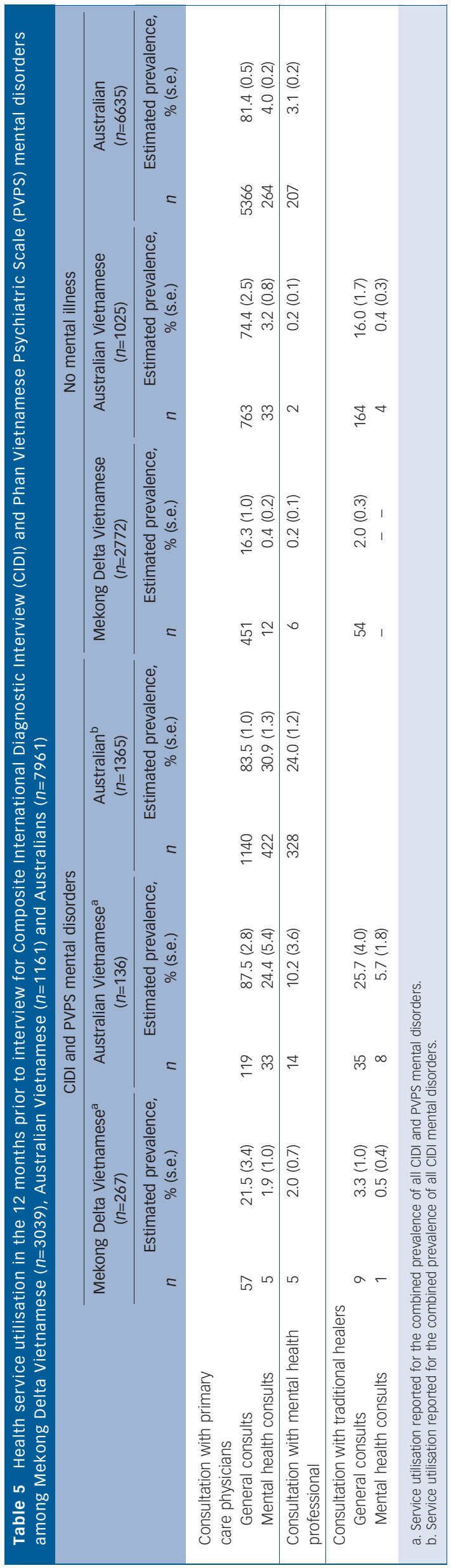

disorders among populations from East Asia. ${ }^{2,5,15,16}$ That trend does not appear to be restricted to studies using the CIDI, with investigations applying other Western-based diagnostic instruments also yielding lower rates of mental disorders among North and South East Asian communities. ${ }^{4,17,18}$

The key question addressed by the present study was whether the addition of a culturally derived diagnostic measure would yield a higher overall prevalence of mental disorder among the Vietnamese. The PVPS added a substantial number of new cases in relation to both Vietnamese populations. Among Mekong Delta Vietnamese the rates increased fourfold. One possibility was that measures such as the PVPS identify individuals with less severe mental disturbances compared with a structured diagnostic instrument. The disability data argue against that conclusion, with those identified by the PVPS being at least as disabled as those identified by the CIDI.

The PVPS somatisation scale accounted for a large percentage of additional cases of mental disorder among Vietnamese in both settings. The importance of the somatic focus among Vietnamese was emphasised further by the higher endorsement of items on the PCS scale of the MOS-SF-12 by Mekong Delta Vietnamese with a mental disorder. This adds to the growing body of literature documenting a preference for reporting distress in the somatic idiom among North and South East Asian populations. ${ }^{5,19,20} \mathrm{~A}$ key implication is that the pre-eminence given to psychological rather than somatic symptoms in the hierarchical organisation of DSM-IV and ICD-10 may result in the under-enumeration of mental disorders in East Asian populations. ${ }^{5}$

The ICD-10-defined category of neurasthenia identified very few participants among the Vietnamese, lower than among the Australian-born. It is noteworthy that in its development, the ICD-10 category was modelled closely on the Western construct of chronic fatigue, ${ }^{21}$ whereas the items included in the PVPS scale have a greater similarity to those defining the category of neurasthenia in the Chinese classification system. ${ }^{22}$

The combined prevalence of CIDI- and PVPS-identified individuals in Vietnam $(8.8 \%)$ and among Vietnamese immigrants $(11.7 \%)$ was lower than that yielded by the CIDI alone among Australians (17.1\%). These findings suggest two broad explanations. First, there may be genuine differences in the vulnerability to common mental disorders across ethnic groups. Alternatively, there may be a threshold effect, with Vietnamese having to experience a greater level of disability than individuals from Western backgrounds before they endorse psychiatric symptoms. Such a tendency may be accounted for by a greater degree of cultural stoicism (suffering without complaint) combined with stigma or feelings of shame associated with revealing mental symptoms in Asian cultures. ${ }^{17,19,23}$ Inconsistent findings have emerged from the international literature in relation to these issues. Simon et al recorded higher levels of disability associated with major depressive disorder in primary care settings for those countries with low prevalence rates. ${ }^{24}$ Patients from North East Asia in particular had both low prevalence rates and high levels of associated disability. In contrast, the World Mental Health Survey ${ }^{1}$ undertaken among general population samples failed to identify an association between lower prevalence rates and greater disability associated with mental disorder across countries.

The CIDI data obtained from Australian Vietnamese suggest that cultural adaptation to Western society may influence the affinity of immigrants for endorsing Western-derived symptoms on instruments such as the CIDI. The rates yielded by the PVPS were similar for the two Vietnamese samples, suggesting that immigrants also retain their culturally based mode of expressing distress, even after a prolonged period of residency in a Western 
country. The AUC data support these inferences by showing greater overlap of the CIDI and PVPS among Australian Vietnamese than Mekong Delta Vietnamese.

Australians and Australian Vietnamese with a mental disorder exhibited much higher consultation rates with primary healthcare physicians than Mekong Delta Vietnamese. The difference in the availability and accessibility of services across the two countries undoubtedly was a major contributor. ${ }^{25}$ The tendency for Australian Vietnamese to restrict their help-seeking to primary care physicians may reflect the stigma associated with mental disorder in that culture and/or the limited availability of mental health professionals from a Vietnamese background residing in Australia.

\section{Limitations}

Several limitations of the study need to be acknowledged. Mekong Delta Vietnamese had a higher response rate compared with the other two samples. Evidence is mixed as to whether people with psychiatric disorders are less likely to participate in surveys. ${ }^{26}$ If that trend pertained in the present study, it would have the effect of attenuating the differences found between the two Australianbased samples and the Mekong Delta Vietnamese group.

There was a difference in the timing of the investigations, with Mekong Delta Vietnamese being studied more recently. If a process of secular shift exerted any influence, it would have lessened differences between Australian Vietnamese and the Mekong Delta Vietnamese because of the recent acceleration of Westernisation in the home country. In keeping with other studies of this type, none of the surveys included the itinerant, those who were homeless or those living in institutions. Low-prevalence disorders such as psychosis and organic disorders were not assessed, nor were the impulse-control disorders included in some recent surveys. ${ }^{1}$

The Australian sample was derived from a national survey. To preserve anonymity of participants, the Australian Bureau of Statistics did not allow extraction of Australians from the specific localities where Australian Vietnamese lived. For logistic reasons, we sampled the Australian Vietnamese in the state of New South Wales, which has the largest concentration of Vietnamese immigrants in the country. We were unable to sample very lowdensity suburbs, possibly excluding more acculturated Vietnamese. The Mekong Delta was chosen because most Vietnamese in Australia are from the south of Vietnam and they originated from both urban and rural areas. Nevertheless, at the time of the study, the lifestyle in the delta may have been more traditional than in the major cities such as Ho Chi Minh where the process of modernisation has gained more ground in recent times.

The level of diagnostic agreement (as indicated by the kappa statistic in Table 4) between the PVPS and the CIDI among Australian Vietnamese was somewhat lower than recorded in the development of the PVPS among a sample of Vietnamese primary care and mental health patients. ${ }^{10}$ The findings are consistent with the general tendency for concordance estimates to be lower in general population samples than in clinical populations. ${ }^{8}$ We note that the level of agreement demonstrated in the present study are comparable with concordance estimates for related diagnostic instruments obtained in other population studies. ${ }^{8,27}$ Our study did not undertake a clinical recalibration of the CIDI with other DSM-IV-based diagnostic instruments. ${ }^{13,16}$ However, studies undertaken among East Asian populations, including neighbouring China, have indicated satisfactory concordance between the CIDI and measures such as the Structured Clinical Interview for DSM-IV in settings where there are similarly low prevalence estimates. ${ }^{16}$ A consistent pattern of low prevalence rates of mental disorder among Vietnamese populations has also been recorded using a range of other measures apart from the CIDI. ${ }^{29,30}$

The cut-off thresholds applied to the sub-domains of the PVPS were derived from naturalist healer diagnoses in primary care and mental health clinical samples and may not generalise to a population setting. ${ }^{28}$ The disability data indicated, however, that people identified by the PVPS and CIDI exhibited the same level of impairment, suggesting that the thresholds applied did not result in the indigenous PVPS detecting less severe cases.

In summary, our findings throw potential light on the large variation in rates of common mental disorders that have emerged from modern epidemiological studies undertaken across nations and regions. Several factors may be relevant in explaining this pattern. Cultural variation in the disability threshold for reporting symptoms may be relevant but results are inconsistent., ${ }^{14}$ Culture-specific ways of expressing mental symptoms appear to be of great importance, with the present study indicating that the addition of an indigenous measure to the CIDI identified many more cases of equal disability among Vietnamese in two settings. The data also suggest that immigration and acculturation to Western environments may alter patterns of symptom endorsement. Vietnamese immigrants retained their base rate of indigenously defined disorders but exhibited higher rates of Western-derived diagnoses. It seems likely that by becoming more familiar with a Western culture, ethnic groups such as the Vietnamese develop a greater affinity for the host society's idiom for expressing mental distress. As a consequence, responses to Western and indigenous measures are likely to show a greater overlap among immigrants. The rapidity of cultural change around the world suggests that the balance between indigenous and Western modes of expressing psychological distress may evolve in a dynamic manner, making it vital to monitor both domains of symptom expression in transcultural settings over time. $^{31}$

The outcomes of the research suggest that it is feasible to integrate universalistic (etic) and culturally specific (emic) approaches ${ }^{28,31,32}$ in studying the mental health of ethnic groups such as the Vietnamese and, by extension, other populations from non-Western traditions. The data demonstrate that a sole reliance on diagnostic systems developed in the West runs the risk of underestimating mental health needs in regions such as South East Asia. Assuming that the rates of mental disorder are low in these settings may inadvertently retard the development of mental health services in the very settings where, as shown by the present study, the majority of people with mental disorders do not have access to appropriate care. ${ }^{33}$

\footnotetext{
Zachary Steel, PhD, MClinPsychol, Derrick Silove, MD, MB ChB(Honsl), FRANZCP, Centre for Population Mental Health Research and Psychiatry Research and Teaching Unit, School of Psychiatry, University of New South Wales, Australia; Nguyen Mong Giao, MD, MB ChB, Department of Psychiatry, Cần Tho University, Vietnam; Thuy Thi Bich Phan, MD, Mb ChB, Tien Chey, MAppStat, BSc, Centre for Population Mental Health Research and Psychiatry Research and Teaching Unit, School of Psychiatry, University of New South Wales, Australia; Anna Whelan, PhD, BA(Honsl), School of Public Health and Community Medicine, University of New South Wales, Australia; Adrian Bauman, PhD, FAFPHM, School of Public Health, Sydney University, Australia; Richard A. Bryant, PhD, MPsychol, University of New South Wales, Australia
}

Correspondence: Zachary Steel, Centre for Population Mental Health Research Level 1, Mental Health Centre, The Liverpool Hospital, Cnr Forbes and Campbell Streets, Liverpool NSW 2170, Australia. Email: z.steel@unsw.edu.au

First received 6 Feb 2008, final revision 25 Sep 2008, accepted 29 Oct 2008

\section{Funding}

This research was supported in part by an Australian National Health and Medical Research Council Program Grant (300304) 


\section{References}

1 Demyttenaere K, Bruffaerts R, Posada-Villa J, Gasquet I, Kovess V, Lepine JP, et al. Prevalence, severity, and unmet need for treatment of mental disorders in the World Health Organization World Mental Health Surveys. JAMA 2004; 291: 2581-90.

2 WHO International Consortium in Psychiatric Epidemiology. Cross-national comparisons of the prevalences and correlates of mental disorders. Bull World Health Organ 2000; 78: 413-26.

3 Hwu HG, Yeh EK, Chang LY. Prevalence of psychiatric disorders in Taiwan defined by the Chinese Diagnostic Interview Schedule. Acta Psychiatr Scand 1989; 79: 136-47.

4 Lee CK, Kwak YS, Yamamoto J, Rhee H, Kim YS, Han JH, et al. Psychiatric epidemiology in Korea. Part I: Gender and age differences in Seoul. J NerV Ment Dis 1990; 178: 242-6.

5 Shen YC, Zhang MY, Huang YQ, He YL, Liu ZR, Cheng H, et al. Twelve-month prevalence, severity, and unmet need for treatment of mental disorders in metropolitan China. Psychol Med 2006; 36: 257-67.

6 Steel Z, Silove D, Chey T, Bauman A, Phan T, Phan T. Mental disorders, disability and health service use amongst vietnamese refugees and the host Australian population. Acta Psychiatr Scand 2005; 111: 300-9.

7 Australian Bureau of Statistics. National Survey of Mental Health and Wellbeing. Profile of Adults, Australia. Australian Bureau of Statistics, 1998

8 Andrews G, Peters L. The psychometric properties of the Composite International Diagnostic Interview. Soc Psychiatry Psychiatr Epidemiol 1998; 33: $80-8$.

9 World Health Organization. The ICD-10 Classification of Mental and Behavioral Disorders. WHO, 1992.

10 Phan T, Steel Z, Silove DM. An ethnographically derived measure of anxiety, depression and somatization: the Phan Vietnamese Psychiatric Scale. Transcult Psychiatry 2004; 41: 200-32.

11 Bracken BA, Barona A. State of the art procedures for translating, validating and using psychoeducational tests in cross-cultural assessment. Sch Psychol Int 1991: 12: 119-32.

12 Kessler RC, Abelson J, Demler O, Escobar Jl, Gibbon M, Guyer ME, et al. Clinical calibration of DSM-IV diagnoses in the World Mental Health (WMH) version of the World Health Organization (WHO) Composite International Diagnostic Interview (WMHCIDI). Int J Methods Psychiatr Res 2004; 13: 122-39.

13 Haro JM, Arbabzadeh-Bouchez S, Brugha TS, de Girolamo G, Guyer ME, Jin R et al. Concordance of the Composite International Diagnostic Interview Version 3.0 (CIDI 3.0) with standardized clinical assessments in the WHO World Mental Health surveys. Int J Methods Psychiatr Res 2006; 15: 167-80.

14 Landis JR, Koch GG. The measurement of observer agreement for categorical data. Biometrics 1977; 33 :159-74.

15 Kawakami N, Shimizu H, Haratani T, Iwata N, Kitamura T. Lifetime and 6month prevalence of DSM-III-R psychiatric disorders in an urban community in Japan. Psychiatr Res 2004; 121: 293-301.
16 Lee S, Tsang A, Zhang M-Y, Huang Y-Q, He Y-L, Liu Z-R, et al. Lifetime prevalence and inter-cohort variation in DSM-IV disorders in metropolitan China. Psychol Med 2007; 37: 61-71.

17 Compton WM 3rd, Helzer JE, Hwu HG, Yeh EK, McEvoy L, Tipp JE, et al. New methods in cross-cultural psychiatry: psychiatric illness in Taiwan and the United States. Am J Psychiatry 1991; 148: 1697-704.

18 Parker G, Chan B, Hadzi-Pavlovic D. Lower rates of depression in westernised Chinese in the US. J Affect Disord 2007; 104: 175-8.

19 Ryder AG, Yang J, Zhu X, Yao S, Yi J, Heine SJ, et al. The cultural shaping of depression: somatic symptoms in China, psychological symptoms in North America? J Abnorm Psychol 2008; 117: 300-13.

20 Lin EH, Ihle LJ, Tazuma L. Depression among Vietnamese refugees in a primary care clinic. Am J Med 1985; 78: 41-4.

21 Paralikar V, Sarmukaddam S, Agashe M, Weiss MG. Diagnostic concordance of neurasthenia spectrum disorders in Pune, India. Soc Psychiatry Psychiatr Epidemiol 2007; 42: 561-72.

22 Lee S. From diversity to unity. The classification of mental disorders in 21stcentury China. Psychiatr Clin North Am 2001; 24: 421-31.

23 Beiser M, Fleming JA. Measuring psychiatric disorder among Southeast Asian refugees. Psychol Med 1986; 16: 627-39.

24 Simon GE, Goldberg DP, Von Korff M, Ustun TB. Understanding cross-national differences in depression prevalence. Psychol Med 2002; 32: 585-94.

25 Wang PS, Aguilar-Gaxiola S, Alonso J, Angermeyer MC, Borges G, Bromet EJ, et al. Use of mental health services for anxiety, mood, and substance disorders in 17 countries in the WHO world mental health surveys. Lancet 2007; 370: 841-50.

26 Kessler RC, Chiu WT, Demler O, Merikangas KR, Walters EE, Merikangas KR. Prevalence, severity, and comorbidity of 12-month DSM-IV disorders in the National Comorbidity Survey Replication. Arch Gen Psychiatry 2005; 62: 617-27.

27 Kessler RC, Wittchen HU, Abelson JM, McGonagle KA, Schwartz N, Kendler KS, et al. Methodological studies of the Composite International Diagnostic Interview (CIDI) in the US National Comorbidity Survey (NCS). Int J Methods Psychiatr Res 1998; 7: 33-55.

28 Van Ommeren M. Validity issues in transcultural epidemiology. $\mathrm{Br} \mathrm{J}$ Psychiatry 2003; 182: 376-8.

29 Beiser M, Hou F. Language acquisition, unemployment and depressive disorder among Southeast Asian refugees: a 10 year study. Soc Sci Med 2001; 53: 1321-34.

30 Hinton WL, Chen YC, Du N, Tran CG, Lu FG, Miranda J, et al. DSM-III-R disorders in Vietnamese refugees. Prevalence and correlates. J Nerv Ment Dis 1993; 181: 113-22.

31 Kirmayer $\amalg$. Beyond the 'new cross-cultural psychiatry': cultural biology, discursive psychology and the ironies of globalization. Transcult Psychiatry 2006; 43: 126-44.

32 Patel V. Cultural factors and international epidemiology. Br Med Bull 2001; 57: 33-45.

33 Saxena S, Thornicroft G, Knapp M, Whiteford H. Resources for mental health: scarcity, inequity, and inefficiency. Lancet 2007; 370: 878-89. 